\title{
A Study of Intercellular Spaces in the Rabbit Jejunum during Acute Volume Expansion and after Treatment with Cholera Toxin
}

\author{
Donald R. DiBona, Lincoln C. Chen, and Geoffrey W. G. Sharp \\ From the Department of Medicine, Massachusetts General Hospital, Boston, \\ Massachusetts 02114 and the Departments of Anatomy and Physiology, Harvard \\ Medical School, Boston, Massachusetts 02115
}

A B S T R A C T The effects of acute volume expansion and of intraluminal administration of cholera toxin have been examined in rabbit jejunum.

Acute volume expansion was shown to reverse the normal reabsorptive flux of water and cause significant fluid secretion. Phase and electronmicroscopic examination of the jejunal epithelium showed that marked distension of the intercellular spaces had occurred. Examination of the jejunal epithelium after treatment with cholera toxin showed that, in association with high rates of fluid secretion, the intercellular spaces were extremely small and lateral membranes of adjacent cells were in close apposition to one another. Thus the mechanisms of fluid secretion in these two situations would appear to be quite different. The secretion associated with volume expansion, and accompanied by a rise in venous pressure and bullous deformations of terminal junctions, could well be due to hydrostatic pressure applied through intercellular channels. The secretion of cholera appears to be unrelated to hydrostatic pressure and is more likely due to body-to-lumen active ion transport.

\section{INTRODUCTION}

Cholera toxin and expansion of extracellular fluid volume are both known to reverse net reabsorption of fluid in the small intestine and to cause fluid secretion (1-4). Several explanations have been proposed to explain the mechanisms of these effects. In the case of cholera toxin, it is known that adenylate cyclase activity in

Dr. Chen's present address is Ford Foundation, P.O. Box 98, Ramna, Dacca 2, Bangladesh.

Received for publication 13 September 1972 and in revised form 4 January 1974. the intestinal epithelial cells is elevated and an increased intracellular concentration of cyclic AMP is thought to mediate the movement of fluid from body to lumen (5-10). The precise details of the bidirectional electrolyte flux changes resulting in osmotic water flow are still subject to discussion. Stimulation of active anion secretion or secretion via a neutral coupled pump is possible, and it is uncertain whether the active sodium reabsorptive mechanism is or is not inhibited simultaneously. The mechanism of secretion during expansion of fluid volume is also controversial $(4,11)$. The possibility of a natriuretic hormone causing decreased lumen-to-body sodium reabsorption has been postulated (12), as has the possibility that the effects are due to hydrostatic pressure changes and increased passive, body-to-lumen movement of water and electrolytes (11).

Recent studies have stressed the importance of the intercellular spaces in the mechanism of fluid movement across epithelial tissue. For instance, intercellular spaces can be seen to be open during active sodium reabsorption when fluid is being reabsorbed, and closed when such movement is inhibited or prevented (13). Thus, it seemed worthwhile to study the intercellular spaces in situations where the movement of fluid and electrolytes was in the direction of body to lumen, and in which dissimilar mechanisms might be contributing to the effects; that is, stimulation of active secretion during cholera, and body-to-lumen movement generated either by hydrostatic pressure changes or by a natriuretic factor in the case of intracellular fluid expansion.

\section{METHODS}

Volume loading studies. New Zealand white rabbits weighing from 1.8 to $2.5 \mathrm{~kg}$ were given food and water 
ad lib until the day of study. After anesthesia with intravenous pentobarbital $(20 \mathrm{mg} / \mathrm{kg})$, the animals were placed on a surgical table with a heating blanket to maintain a constant body temperature. A tracheotomy was performed and the right jugular vein was catheterized with polyethylene tubing (i.d. 0.3 in) connected to an intravenous infusion containing sterile normal saline. The intravenous line was kept open at a rate which did not exceed $0.2 \mathrm{ml} / \mathrm{min}$ until volume loading commenced. Through a midline incision the small intestine was exposed and a $10-\mathrm{cm}$ loop of jejunum was isolated beginning $8-10 \mathrm{~cm}$ caudad to the ligament of Treitz. Polyethylene catheters (ID $2.5 \mathrm{~mm}$ ) were inserted into the cephalad and caudad ends of the loop via small incisions along the antimesenteric surface. The catheters were gently tied into place with silk sutures, while care was taken to preserve normal blood supply to the study loops. The small intestine was then returned into the abdominal cavity with the catheters leading through the incision in the body wall, and the opening closed with metal clips. The cephalad catheter was connected to a Sigmamotor pump (Sigmamotor, Inc., Middleport, N. Y.), and the caudad catheter drained into a graduated cylinder. All solutions infused into the loop were prewarmed to $37^{\circ} \mathrm{C}$ in a constant temperature water bath. The loop was cleaned by infusion of normal saline until the drain fluid was completely clear.

To begin the water flux studies, the infusion solution was changed to a perfusate containing: $137 \mathrm{mM} \mathrm{NaCl}$; $2.7 \mathrm{mM} \mathrm{KCl} ; 12 \mathrm{mM} \mathrm{NaHCO} ; 0.4 \mathrm{mM} \mathrm{NaH} \mathrm{NOO}_{4} ; 1.8$ $\mathrm{mM} \mathrm{MgCl}{ }_{2}$; and phenolsulfonphthalein (PSP), $2 \mathrm{mg} /$ $100 \mathrm{ml}\left(280\right.$ mosmol/ $\left.\mathrm{kg} \mathrm{H} \mathrm{H}_{2} \mathrm{O} ; \mathrm{pH} 7.8\right)$. The pump rate was calibrated to deliver $1 \mathrm{ml} / \mathrm{min}$ of perfusate into the loop. After an equilibration period of $20-30 \mathrm{~min}$, control net water flux studies were performed by collecting the effluent from the cauded catheter for $15 \mathrm{~min}$. Two to four such 15-min collections were made for control flux measurements.

Volume loading was initiated by infusing sterile normal saline, at a rate of $5 \mathrm{ml} / \mathrm{min}$, through the jugular catheter. After reaching approximately $10 \%$ of total body weight the perfusate pump rate was continued at $1 \mathrm{ml} / \mathrm{min}$ and another 20-30 min was permitted for full equilibration. Two to four 15-min collections of effluent constituted the net water flux studies for the volume-loaded state.

In vivo preparation of jejunal tissue for morphological studies. Control tissue was obtained immediately after termination of control flux collections and before volume loading. The jejunum was re-exposed and a $2-\mathrm{cm}$ segment of jejunum proximal to the study loop, but with a distinctly different mesenteric blood supply, was tied off. Through the antimesenteric surface $1 \mathrm{ml}$ of $2 \%$ glutaraldehyde in Tyrode's solution was injected intraluminally. After 5 min the segment was removed and placed into a large volume of $2 \%$ glutaraldehyde in Tyrode's solution, where several small (ca. $1 \mathrm{~mm}^{8}$ ) pieces were cut from it. The small pieces were fixed an additional hour in glutaraldehyde (at $4^{\circ} \mathrm{C}$ ), post-fixed in osmium, dehydrated in a graded series of ethanols and embedded in an Epon-Araldite mixture (Ciba Products Co., Summit, N. J.) (14) for subsequent microscopic examination. All tissue samples were coded and interpreted blind. Intestinal bleeding was minimized by tying the mesenteric circulation supplying the removed segment. After completion of the net water flux studies during volume loading, another $2-\mathrm{cm}$ segment was

${ }^{1}$ Abbreviation used in this paper: PSP, phenolsulfonphthalein. removed in a similar fashion. The volume-loaded tissue was adjacent to the control tissue. Cephalad and caudad positions of the control and volume-loaded tissues were varied from one study to another.

Cholera studies. The animal preparation and net water flux measurements were made in an identical manner to the volume-loading studies, with the following exceptions. After control flux studies, the loops were drained and both catheters were clamped. $10 \mu \mathrm{g}$ of purified cholera enterotoxin (15) in $3 \mathrm{ml}$ of normal saline was injected intraluminally. After $45-60 \mathrm{~min}$ the catheters were opened and the loops were permitted to drain freely. $3 \mathrm{~h}$ after cholera enterotoxin exposure, two to four $15-\mathrm{min}$ flux studies were performed. Tissue was removed from both control and cholera-treated loops for morphological studies in the manner described previously.

Measurement of portal venous pressure. After animal preparation the mesenteric vein draining the ascending colon was isolated and catheterized with polyethylene tubing (ID 0.03 in) and connected to a three-way stopcock. One outlet of the stopcock permitted infusion of a $5 \%$ dextrose solution containing $20 \mu \mathrm{g} / \mathrm{ml}$ Heparin to keep the line patent. The second line was connected to a water manometer for pressure determinations. Venous pressure was measured before and after volume expansion.

Calculation of net water flux. The effluent was diluted $1: 4$ with $1.0 \mathrm{~N} \mathrm{NaOH}$ and PSP concentration was determined colorimetrically in a Zeiss spectrophotometer (Carl Zeiss, Inc., New York). True PSP concentration was determined by the following formula, with three wavelengths to correct for any possible interference.

$$
\mathrm{C}=\left(\mathrm{PSP}_{560}\right)-\frac{\left(\mathrm{PSP}_{520}\right)+\left(\mathrm{PSP}_{600}\right)}{2}
$$

where $\mathrm{C}=$ colorimetric reading directly proportional to concentration, $\left(\mathrm{PSP}_{500}\right)=$ optical density at $560 \mathrm{~nm}$, $\left(\mathrm{PSP}_{520}\right)=$ optical density at $520 \mathrm{~nm}$, and $\left(\mathrm{PSP}_{600}\right)=$ optical density at $600 \mathrm{~nm}$.

Net water flux, expressed as microliters per centimeter of jejunum per hour was determined by the following formula:

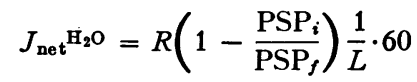

where $J_{\text {not }} \mathbf{B}_{2} \mathbf{O}=$ net water flux in microliters per centimeter per hour, $R=$ pump rate in microliters per minute, PSP، $=\mathrm{PSP}$ concentration, $\mathrm{PSP}_{t}=\mathrm{PSP}$ concentration in the effluent, $L=$ length of loop in centimeters.

Compensation for osmotic effects during fixation. While current evidence suggests that fixation artifacts are minimized when the fixative is added to an already isotonic vehicle (16), there was a possibility that initial exposure to a subsequently hypertonic solution could cause a systematic change in the morphology of the jejunal intercellular spaces. For this reason additional experiments were performed with both volume expansion and cholera toxin, where initial fixation was by injection into the isolated loop of an isotonic fixative composed of a $2 \%$ solution of glutaraldehyde $(200 \mathrm{mM})$ in a threefold dilution of $T y-$ rode's solution (final osmolality of ca. 300 mosmol $/ \mathrm{kg} \mathrm{H}_{2} \mathrm{O}$ in the resulting fixative). Tissue was otherwise processed as before, where subsequent solutions are presented equivalently to each side of the epithelium and thus no osmotically induced configurational changes are anticipated. 
TABLE I

Rabbit Jejunal Net Water Flux during Control Conditions and after Treatment with Cholera Toxin

\begin{tabular}{cccc}
\hline & \multicolumn{3}{c}{ Net water flux } \\
\cline { 2 - 4 } Rabbit & Control & Cholera & $\Delta$ \\
\hline & & $\mu l / c m / h$ \\
2 & -420 & +232 & 652 \\
2 & -104 & +312 & 416 \\
3 & -369 & +296 & 665 \\
4 & -152 & +416 & 568 \\
5 & -136 & +268 & 404 \\
Mean & -236 & +304 & $541 \pm 56$ \\
\hline
\end{tabular}

$P<0.01$

\section{RESULTS}

In Table I are shown the net water fluxes during control conditions and after $3 \mathrm{~h}$ exposure to cholera toxin. In Table II the net water fluxes during control conditions and after volume loading are shown. The difference in fluid movement due to the action of cholera toxin was $541 \mu \mathrm{l} \cdot \mathrm{cm}^{-1} \cdot \mathrm{h}^{-1}$, and due to volume loading was $173 \mu \mathrm{l} \cdot \mathrm{cm}^{-1} \cdot \mathrm{h}^{-1}$. Under both sets of experimental conditions a change from reabsorption to secretion occurred and the changes were highly significant. In a third series of experiments it was shown that volume loading, under these conditions, caused an increase in portal venous pressure from the control value of 6.3 $\mathrm{cm}$ water to $8.7 \mathrm{~cm}$ water. The difference was highly significant $(P<0.01, n=5)$.

Phase and electron microscope examination of the tissues under these three sets of conditions demonstrated

TABLE II

Rabbit Jejunal Net Water Flux during Control Conditions and after Volume Loading

\begin{tabular}{cccr}
\hline & \multicolumn{3}{c}{ Net water flux } \\
\cline { 2 - 4 } Rabbit & Control & $\begin{array}{l}\text { Volume } \\
\text { loading }\end{array}$ & $\Delta$ \\
\hline & & $\mu l / c m / h$ \\
1 & -148 & +80 & 228 \\
2 & -92 & +172 & 264 \\
3 & -16 & +28 & 44 \\
4 & -188 & -80 & 108 \\
5 & -60 & +396 & 456 \\
6 & -88 & -4 & 84 \\
7 & -80 & +108 & 188 \\
8 & -52 & +12 & 64 \\
9 & -80 & +40 & 120 \\
Mean & -89 & +84 & $173 \pm 43$ \\
\hline
\end{tabular}

$P<0.01$ that in jejunal tissue treated with cholera toxin, the intercellular spaces were closed, while after volume loading they were dramatically open. On this basis, it was always possible to identify control and experimental tissues from both cholera toxin and volume expansion experiments. Despite the inherent sampling limitations of electron microscopy, the nature of the results is best appreciated with this technique. Initial discussion is of the results obtained with those tissues fixed first with hypertonic fixative, where examination was more comprehensive.

Examination of control, absorbing loops by phase microscopy revealed a large variability in the degree of intercellular space distension but, even in those that appeared to be the most tightly closed, open (or enlarged) regions were always detected by electron microscopy. Fig. 1 illustrates a portion of villus epithelium from approximately halfway between the villus tip and the opening of the crypt. It is clear that at least in the more basal portion of the epithelium, the intercellular spaces are open. After acute volume expansion, a marked enlargement of the intercellular spaces was observed. While this was particularly prominent in the tips of the villi, the spaces were enlarged throughout the epithelium. Space enlargement of the magnitude seen in Fig. 2 was observed in all four tissues studied and was not seen in eight control tissues.

In contrast to the appearance of tissue during volume expansion, all four of the tissues tested with cholera toxin consistently showed a very strict closure of the intercellular spaces. As can be seen in Fig. 3 there is no visible separation between the cells. The apical junctional complexes in both the control and cholera-treated tissues were normal in appearance, with the outer zone (or tight junction) showing apparent fusion of adjacent cell membranes.

Most of the junctional complexes of volume-loaded epithelia were unaffected, but in three of the four samples examined most thoroughly in this regard, approximately $12 \%$ of the junctions seen showed an internal bullous deformation like that shown in Fig. 4; the fourth sample was apparently free of this deformation while it similarly showed a gross widening of the lateral intercellular spaces. Because of the implications of this junctional deformation in terms of the route of fluid transport, a quantitative estimate of its occurrence was undertaken. In the four volume-expanded samples mentioned, 81 deformed junctions were noted in a total population of 864 observed profiles. Comparable examination of control and cholera-treated tissue showed no such deformations in examined populations of 749 and 890 junctions, respectively. Deformed junctions were found in all portions of the villi but not in the crypts.

1302 D. R. DiBona, L. C. Chen, and G. W. G. Sharp 


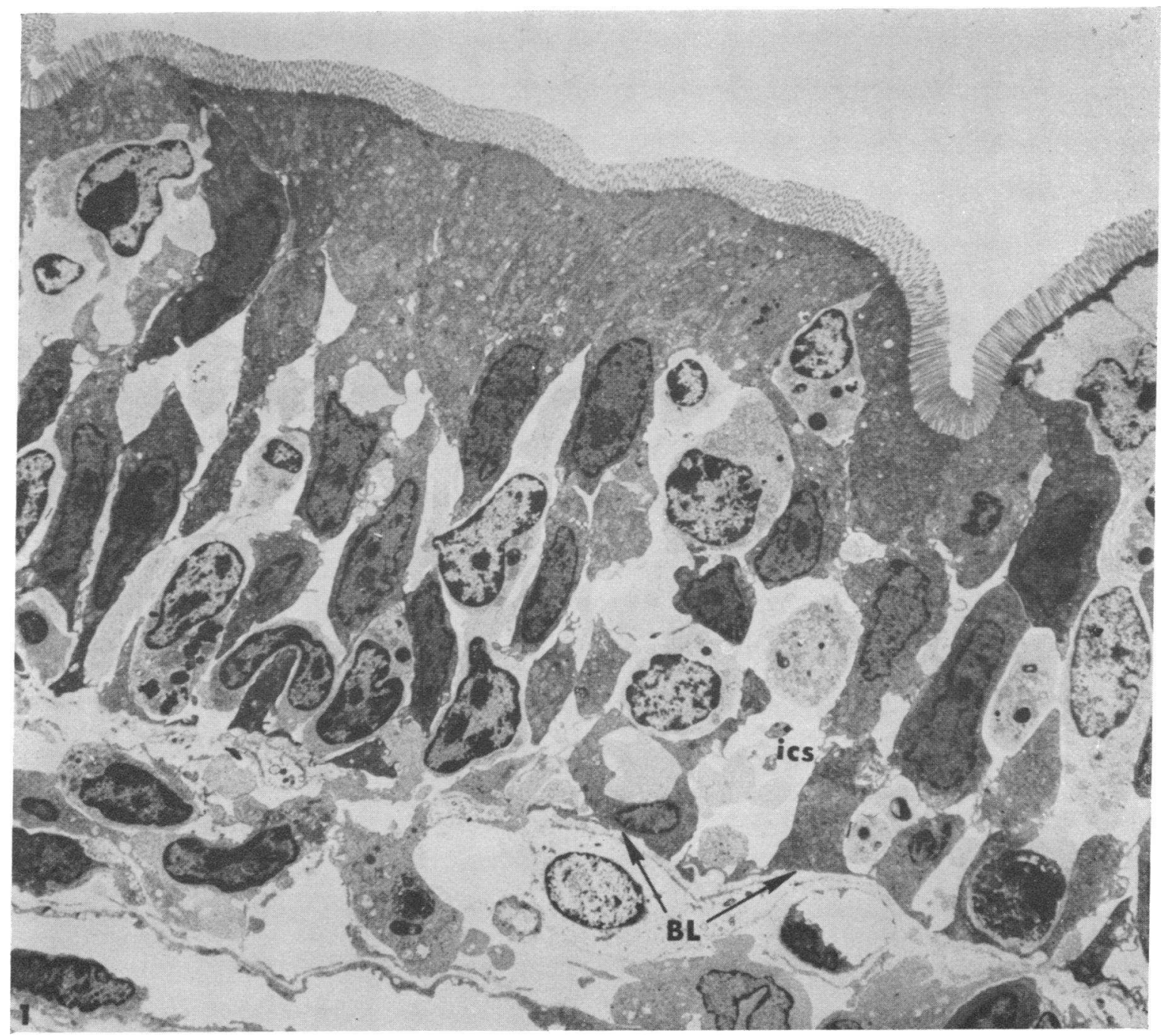

FIGURE 1 Electron micrograph of villus epithelium from control absorbing loop. Intercellular spaces (ics) are clearly open at this magnification. To provide a fair comparison of control and experimental loops, this view and those in Figs. 2 and 3 are taken from a region of epithelium midway between the villus tip and the opening of the adjacent crypt. The orientation of this field and those in succeeding figures is with the intestinal lumen at the top and the basement lamina (BL) at the bottom. $\times 3,300$.

While overall tissue fixation was poor with the isotonic fixation procedure (nonuniform appearance of cell morphology with many regions where cell swelling was evident in control preparations), results with this procedure were consistent with the findings above, in that material was identifiable without prior knowledge of treatment. Volume-expanded samples showed a clear enlargement of intercellular spaces over the respective controls; intercellular spaces were tightly closed compared to controls where tissue had been exposed to cholera toxin. This latter result is illustrated in Fig. 5.

\section{DISCUSSION}

The results of these studies show that when net fluid movement across the jejunal epithelium is from body to lumen, the lateral intercellular spaces will be either open or closed depending on the cause of fluid transport. In tissues where fluid secretion was elicited by treatment with cholera toxin, lateral spaces were closed relative to control tissue; where fluid secretion was due to volume expansion, spaces were open to a much greater extent than in reabsorbing controls. It appears, therefore, that distinctly different mechanisms are operating in the two experimental situations. 

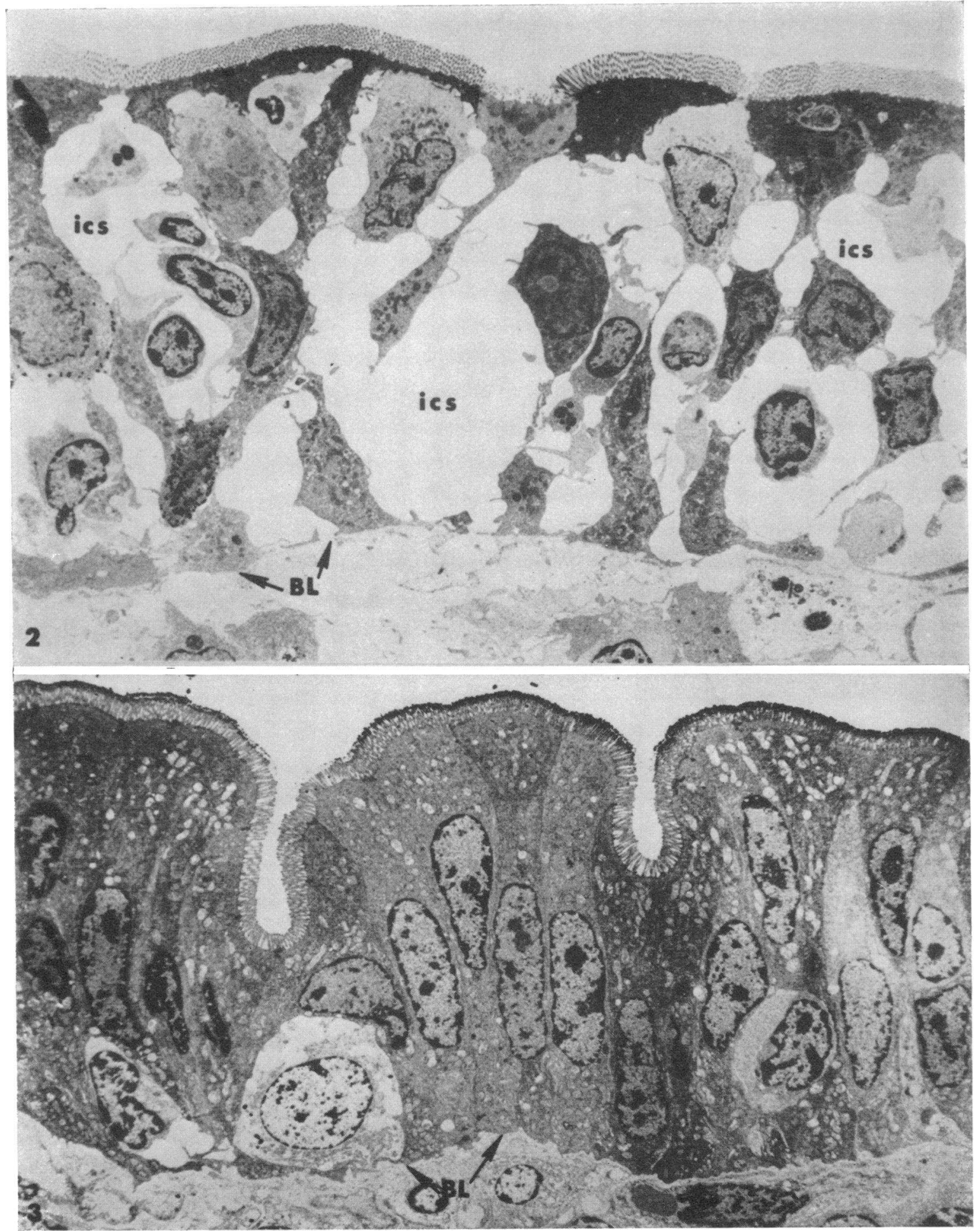

FIGURE 2 Jejunal epithelium from a loop fixed after acute volume expansion. As illustrated here, intercellular spaces (ics) were grossly distended in each of the four volume-expanded preparations. $\times 3,300$.

FIGURE 3 Jejunal epithelium from a loop fixed after treatment with cholera toxin. It is 
Closure of the intercellular spaces after treatment with cholera toxin is in keeping with previous studies of lateral space geometry and epithelial fluid transport. Intestinal epithelium is regarded generally as a system that behaves predictably within the "standing-gradient" hypothesis $(13,17)$, with the lateral intercellular spaces constituting the middle compartment in the three-compartment concept of Curran and MacIntosh (18). These theoretical considerations predict space closure in "backwards-transporting" or secretory epithelia (19). Inhibition of mucosa to serosa ion transport has been shown to be accompanied by space closure in intestinal epithelium (20) and in gall bladder (13), and in each of these tissues lateral spaces are closed when osmotic forces produce a fluid flow from body to lumen (21, 22).

In light of the demonstrated increase in adenylate cyclase activity produced by cholera toxin (6) and since water transport is passive, the structural localization of secretory active ion transport is of considerable interest. Three general sets of circumstances should be considered: $(a)$ active transport of anions from lateral intercellular spaces into the cell interior (with accompanying cation and water flux across the cells to the lumen); (b) active extrusion at the cell surfaces in the crypts or the villi or both with passive flow of water either across the luminal cell membrane or extracellularly through the apical junctions; (c) suppressed reabsorption from the lumen. The present morphologic findings, unfortunately, are in accord with each of these explanations and cannot distinguish between them since intercellular space closure is anticipated in each case. Furthermore, it should be pointed out that intercellular space morphology can be affected by extraepithelial factors: for instance, smooth muscle tone (23). While the morphological results with cholera toxin are unequivocal, it might be suggested that assymetric application of a hypertonic mucosal solution in the initial stage of tissue fixation could affect space closure (21). However, demonstration of the identical phenomenon where initial fixation was with isotonic solution eliminates that possibility and suggests that the systematic difference in intercellular space geometry is indeed an indication of the previous functional state of the tissue. It will not be easy to draw firm conclusions on the relationship between transport changes and structure until in vitro experiments have been completed under strictly controled conditions.

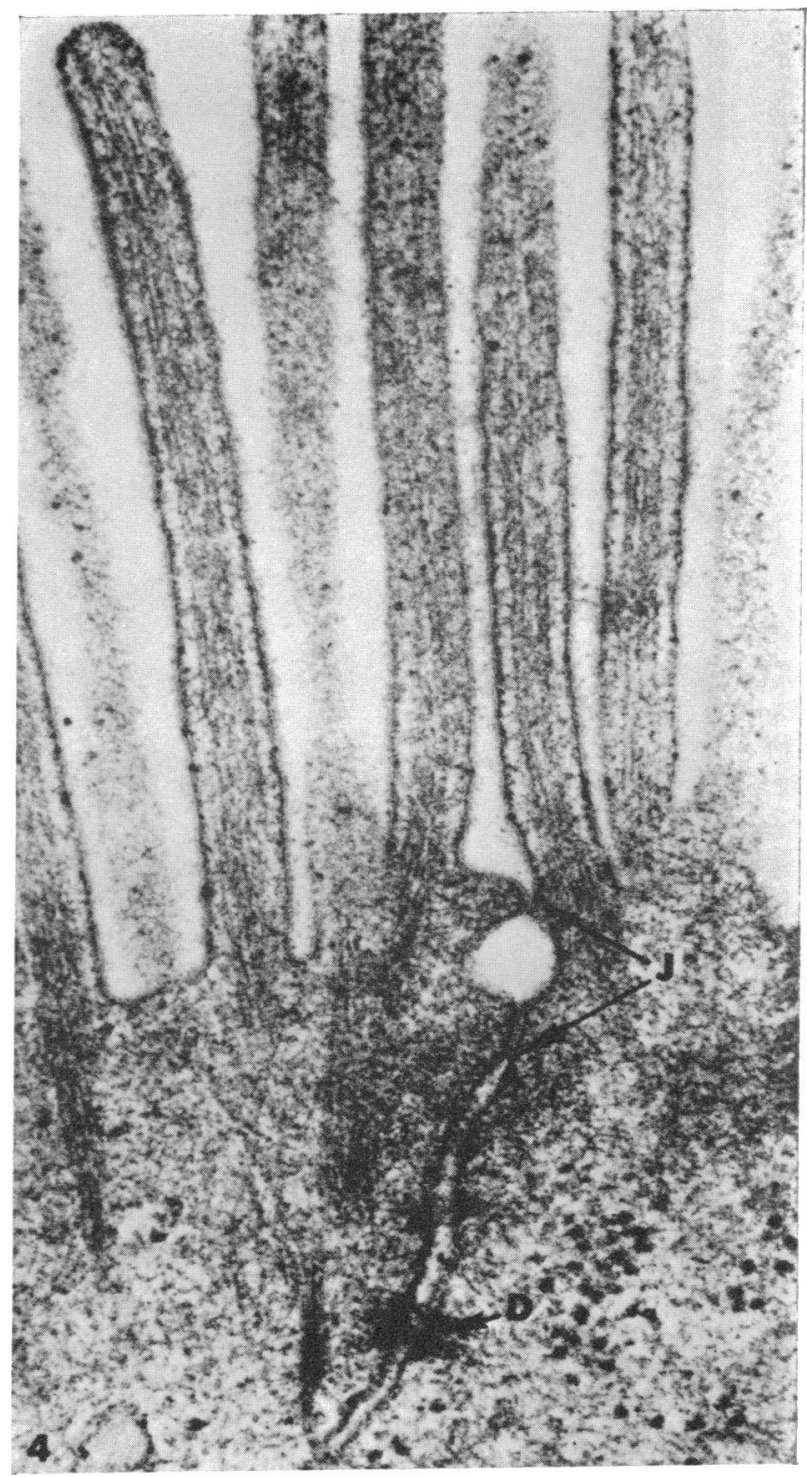

Figure 4 View of the apical cell contacts as observed after acute volume expansion. The "tight" or "limiting" (25) junction $(\mathrm{J})$ between these cells extends between the arrows and is focally interrupted by a bullous deformation or "blister". $\times 60,000$.

The results of volume-loading studies are more readily interpretable. In tissue fixed after volume expansion the dilation of intercellular spaces might be anticipated on the basis of the model proposed by Humphreys and Earley (11). The increased venous pressure

evident that at this magnification no intervening space between cells can be detected. At higher magnifications, in each of the cholera-treated preparations, the cell-to-cell separation was of the order of $200-300 \AA$ except where cell attachments were present. The dense material on the luminal surface is the result of en bloc staining with uranyl acetate and was otherwise not present. $\times 3,300$. 

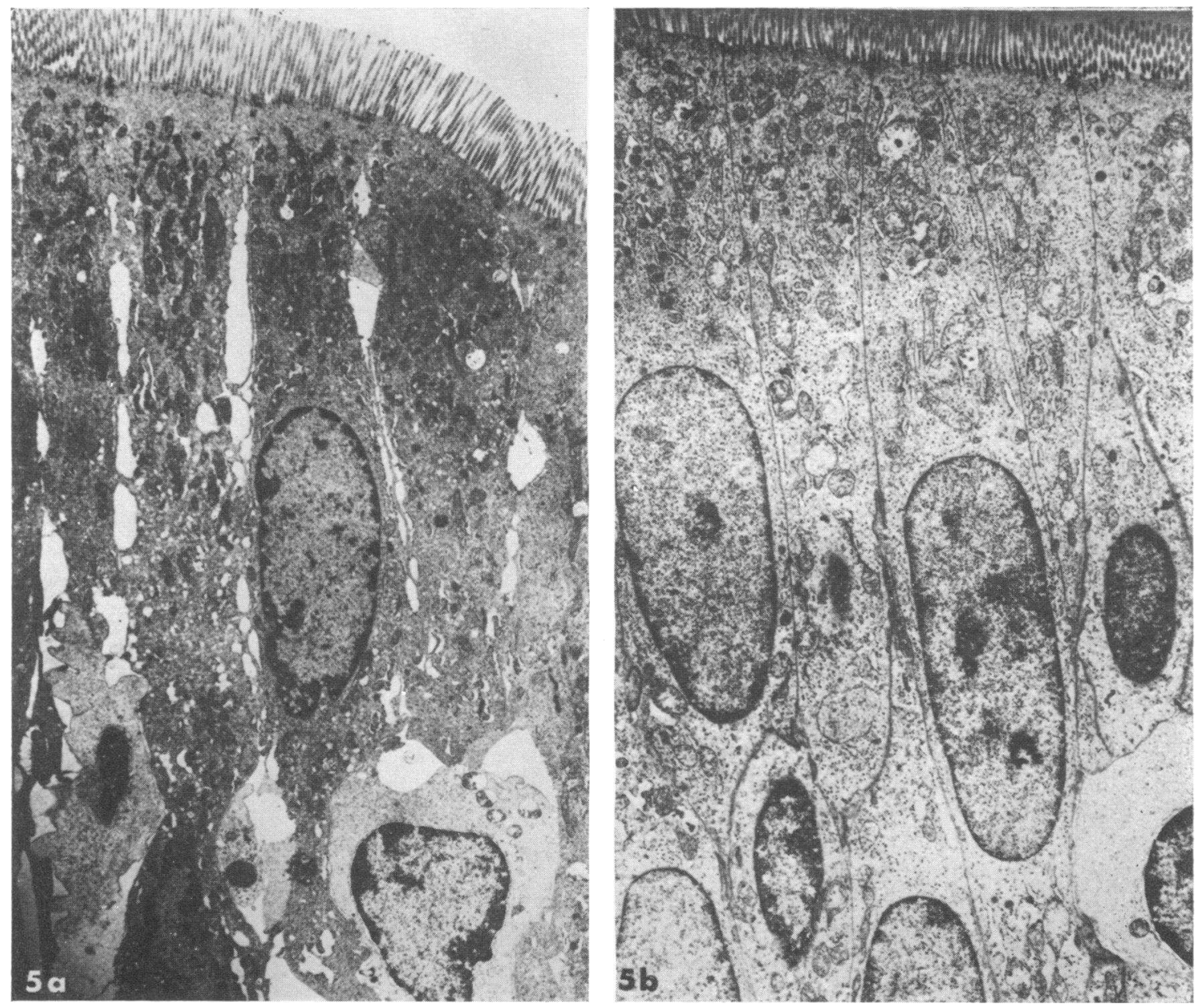

FIGURE 5 (a) Untreated jejunal epithelium fixed with "isotonic" glutaraldehyde (as described in text). This view, as before, is from approximately midway between villus tip and opening of crypt. Intercellular spaces are patent to about the extent observed when initial fixation was hypertonic. $\times 5,500$.

(b) Micrograph of cholera toxin-treated sample fixed as in $a$ and from comparable portion of villus. Intercellular spaces are closed tightly. The suggestion of a mild cell swelling was not a uniform finding in this sample and was observed with spotty occurrence in control and volume-loaded tissues as well. The overall quality of cell fixation with this technique was poor and highly variable while the geometry of the intercellular spaces was consistently as described with addition of $2 \%$ glutaraldehyde to an isotonic vehicle. $\times 5,500$.

observed after volume expansion seems to exert sufficient hydrostatic force on the serosal aspect of the epithelium to force fluid into the spaces between cells. Translation of this pressure to the apical cell-cell seals might subsequently force fluid into the lumen through this extracellular route. Indeed, increased venous pressure has been shown to cause fluid flow into the lumen (24). Recent evidence of the large extracellular conductance of intestinal epithelium (25) would suggest that the "tight" junctions in this tissue constitute less resistance to hydraulic flow than has been anticipated on the basis of junction morphology. The increased permeability of the intestine to inulin (11) may be evidence for the extracellular passage of fluid into the lumen, as inulin passage through the cells is considered unlikely. In this regard, the observation that many of the apical junctions are altered during volume-expansion is of considerable interest and may be construed as further evidence that the fluid route is extracellular. Comparable deformation of the apical tight junctions has been observed also in toad bladder and skin (26, 27) under conditions where a serosal-to-mucosal fluid flow was experimentally produced.

Acute volume expansion appears to cause an eleva- 
tion of serosal hydrostatic pressure sufficient to drive fluid into the space between cells and subsequently through the rate-limiting apical (tight) junctions to the lumen. Thus, there would seem to be no need for a chemical mediator to explain the effects of acute volume expansion, and our results strongly support the model proposed by Humphreys and Earley (11).

In conclusion, it is clear that the mechanism of fluid secretion in intestinal epithelium is quite different after exposure to cholera toxin and during acute volume expansion. The morphologic changes seen are incompatible with the explanation that toxin-stimulated fluid movement is caused by a hydrostatic pressure effect, but are consistent with a change in the ion transport properties of the epithelial cells. Contrarily, the effect of volume expansion is probably mediated by increased hydrostatic pressure and not by changes in active ion transport.

\section{ACKNOWLEDGMENTS}

The authors are grateful to Dr. Richard Finkelstein, Dallas, Texas, for supplies of purified cholera enterotoxin and to Patricia Witkum and Bonnie Lord for their skilled assistance.

The investigation was supported by a grant from the John A. Hartford Foundation Inc., and by the U. S. Public Health Service, grants HL-06664 from the National Heart Institute and AM-04501 from the National Institute of Arthritis and Metabolic Diseases. Dr. Sharp is supported by a Public Health Service Research Career Development Award of the National Institute of Arthritis and Metabolic Diseases, 1 K04 AM-42376.

\section{REFERENCES}

1. Pierce, N. F., W. B. Greenough, III, and C. C. J. Carpenter, Jr. 1971. Vibrio cholerae enterotoxin and its mode of action. Bacteriol. Rev. 35: 1.

2. Carpenter, C. C. J. 1971. Cholera enterotoxin. Recent investigations yield insights into transport processes. Am. J. Med. 50: 1 .

3. Richet, G., and A. Hornyck. 1969. The effect of an expansion of extracellular fluids on net $\mathrm{Na}$ flux in the jejunum of rats. Nephron. $6: 365$.

4. Higgins, J. T., Jr., and N. P. Blair. 1971. Intestinal transport of water and electrolytes during extracellular volume expansion in dogs. J. Clin. Invest. 50: 2569.

5. Schafer, D. E., W. D. Lust, B. Sircar, and N. O. Goldberg. 1970. Elevated concentration of adenosine $3^{\prime}, 5^{\prime}$ cyclic monophosphate concentration in intestinal mucosa after treatment with cholera toxin. Proc. Natl. Acad. Sci. U.S. A. $67: 851$.

6. Sharp, G. W. G., and S. Hynie. 1971. Stimulation of intestinal adenyl cyclase by cholera toxin. Nature (Lond.). 229: 266.

7. Kimberg, D. V., M. Field, J. Johnson, A. Henderson, and E. Gershaw. 1971. Stimulation of intestinal mucosal adenyl cyclase by cholera enterotoxin and protaglandins. J. Clin. Invest. 50: 1218.

8. Chen, L. C., J. E. Rohde, and G. W. G. Sharp. 1971. Intestinal adenyl-cyclase activity in human cholera. Lancet. 1: 939.
9. Chen, L. C., J. E. Rohde, and G. W. G. Sharp. 1972. Properties of adenyl cyclase from human jejunal mucosa during naturally acquired cholera and convalescence. J. Clin. Invest. $51: 731$.

10. Guerrant, R. L., L. C. Chen, and G. W. G. Sharp. 1972. Intestinal adenyl-cyclase activity in canine cholera: correlation with fluid accumulation. J. Infect. Dis. $125: 377$.

11. Humphreys, M. H., and L. E. Earley. 1971. The mechanism of decreased intestinal sodium and water absorption after acute volume expansion in the rat. $J$. Clin. Invest. 50: 2355.

12. Johnston, C. J., and J. O. Davis. 1966. Evidence from cross circulation studies for a humoral mechanism in the natriuresis of saline loading. Proc. Soc. Exp. Biol. Med. $121: 1058$.

13. Tormey, J. McD., and J. M. Diamond. 1967. The ultrastructoral route of fluid transport in rabbit gall bladder. J. Gen. Physiol. 50 : 2031.

14. DiBona, D. R., M. M. Civan, and A. Leaf. 1969. The anatomic site of the transepithelial permeability barriers of toad bladder. J. Cell Biol. 40: 1.

15. Finkelstein, R. A., and J. J. LoSpalluto. 1970. Production of highly purified choleragen and choleragenoid. J. Infect. Dis. Suppl. 121: 63.

16. Bone, Q., and K. P. Ryan. 1972. Osmolarity of osmium tetroxide and glutaraldehyde fixatives. Histochem. J. 4: 331 .

17. Diamond, J. M., and W. H. Bossert. 1967. Standinggradient osmotic flow: a mechanism for coupling of water and solute transport in epithelia. J. Gen. Physiol. 50: 2061.

18. Curran, P. F., and J. R. MacIntosh. 1962. A model system for biological water transport. Nature (Lond.). $193: 347$.

19. Diamond, J. M., and W. H. Bossert. 1968. Functional consequences of ultrastructural geometry in "backwards" fluid-transporting epithelia. J. Cell Biol. 37: 694.

20. Sjöstrand, F. S. 1963. The ultrastructure of the plasma membrane of columnar epithelium cells of the mouse intestine. J. Ultrastruct. Res. 8: 517.

21. Loeschke, K., C. J. Bentzel, and T. Z. Csaky. 1970. Assymetry of osmotic flow in frog intestine: functional and structural correlation. Am. J. Physiol. 218: 1723.

22. Smulders, A. P., J. McD. Tormey, and E. M. Wright. 1972. The effect of osmotically induced water flows on the permeability and ultrastructure of the rabbit gall bladder. J. Membrane Biol. 7 : 164.

23. DiBona, D. R., and M. M. Civan. 1970. The effect of smooth muscle on the intercellular spaces in toad urinary bladder. J. Cell Biol. 46: 235.

24. Hakim, A. A., and N. Lifson. 1969. Effects of pressure on water and solute transport by dog intestinal mucosa in vitro. Am. J. Physiol. 216: 276.

25. Frizzell, R. A., and S. G. Schultz. 1972. Ionic conductances of extracellular shunt pathway in rabbit ileum. Influence of shunt on transmural sodium transport and electrical potential differences. J. Gen. Physiol. 59: 318.

26. DiBona, D. R. 1972. Passive intercellular pathway in amphibian epithelia. Nat. New Biol. 238: 179.

27. DiBona, D. R., and M. M. Civan. 1973. Pathways for movement of ions and water across toad urinary bladder. I. Anatomic site of transepithelial shunt pathways. $J$. Membrane Biol. 12: 101. 